\title{
Correction to: MicroRNAomic Transcriptomic Analysis Reveal Deregulation of Clustered Cellular Functions in Human Mesenchymal Stem Cells During in Vitro Passaging
}

\author{
Shuh-Wen Aung ${ }^{1} \cdot$ Noor Hayaty Abu Kasim ${ }^{1} \cdot$ Shamsul Azlin Ahmad Shamsuddin ${ }^{2} \cdot$ Thamil Selvee Ramasamy $^{3}$
}

Published online: 17 July 2020

(C) Springer Science+Business Media, LLC, part of Springer Nature 2020

Correction to: Stem Cell Reviews and Reports 16(1):222-238

https://doi.org/10.1007/s12015-019-09924-0

The original version of this article unfortunately contained a mistake. The current Figure 1 in the proofs is not updated. The correct Figure 1 is shown here.

The online version of the original article can be found at https://doi.org/ 10.1007/s12015-019-09924-0

Thamil Selvee Ramasamy

selvee@ummc.edu.my

1 Department of Restorative Dentistry, Faculty of Dentistry, University of Malaya, 50603 Kuala Lumpur, Malaysia

2 Institute of Biological Sciences, Faculty of Science, University of Malaya, 50603 Kuala Lumpur, Malaysia

3 Stem Cell Biology Laboratory, Department of Molecular Medicine, Faculty of Medicine, University of Malaya, 50603 Kuala

Lumpur, Malaysia 
(a)

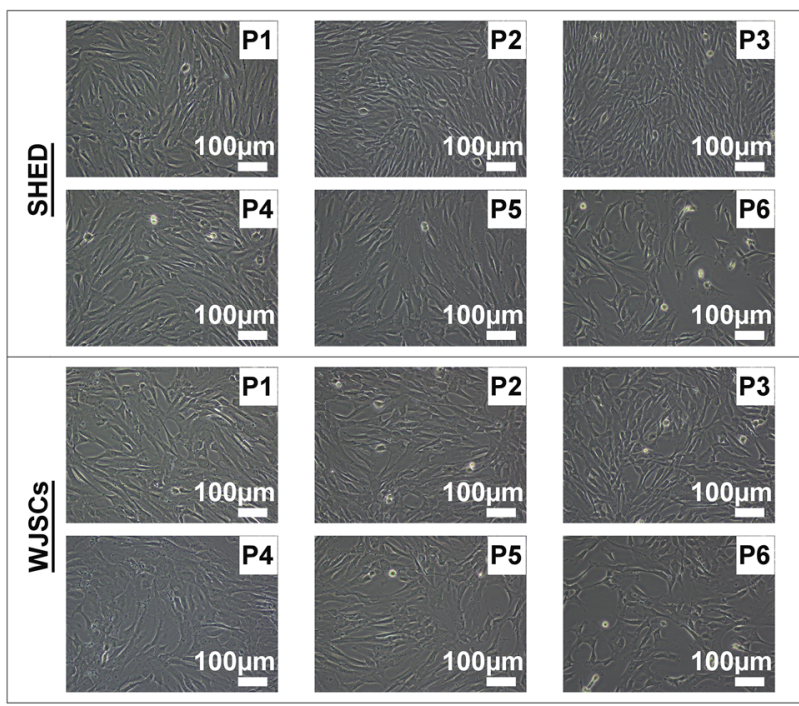

(c)



(e)

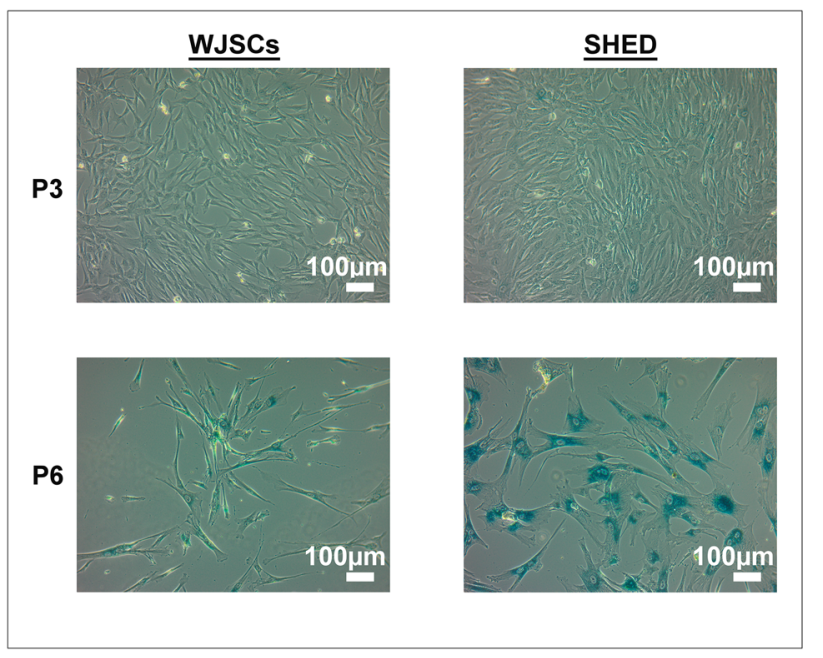

(b)

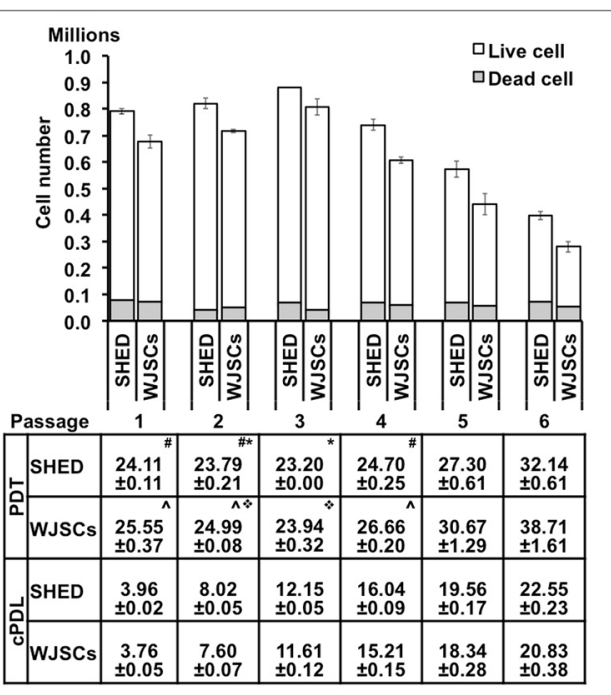

(d)

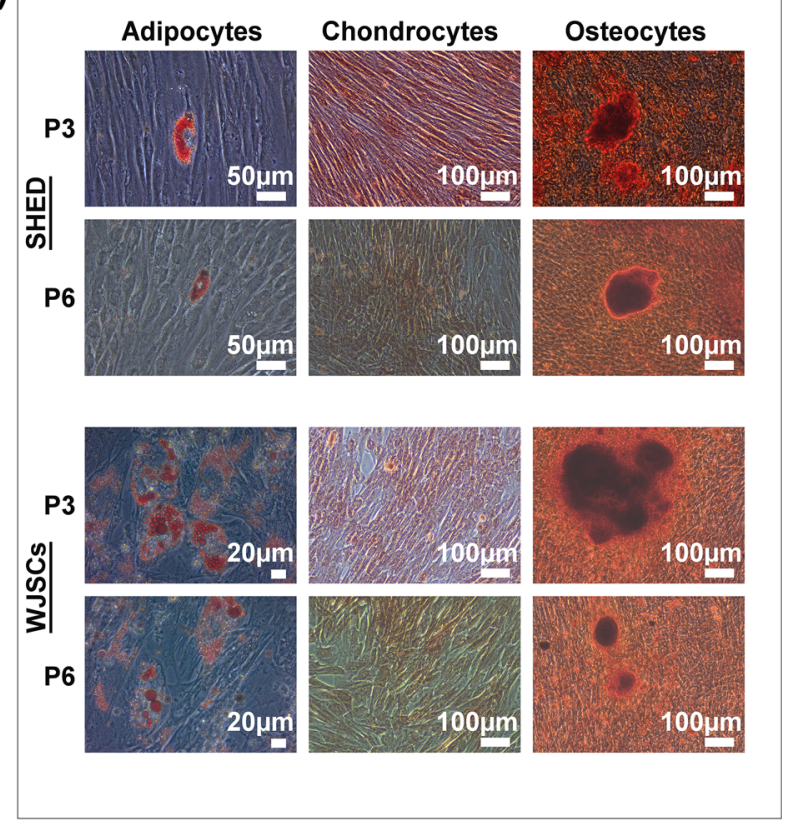

(f)

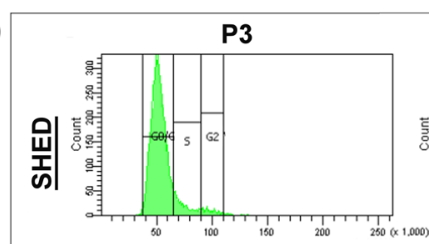

G1 : $46.37 \% \pm 2.80$

S : $5.60 \% \pm 1.39$

G2 : $1.93 \% \pm 0.40^{*}$

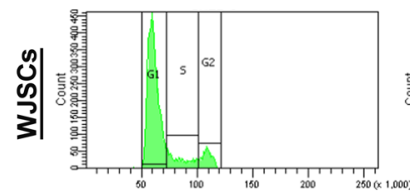

G1 : $43.37 \% \pm 2.57$

S : $: 14.27 \% \pm 1.96$

G2 : $3.57 \% \pm 0.25$ \#

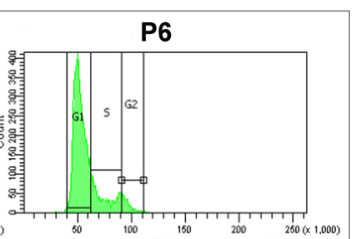

G1 : $41.00 \% \pm 5.52$

S : $6.20 \% \pm 0.95$ G2 : $4.73 \% \pm 1.15^{\star}$

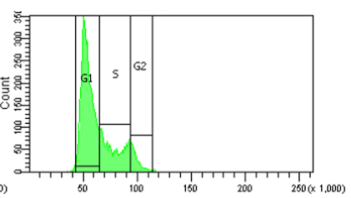

G1 : $38.27 \% \pm 4.37$

S : $13.67 \% \pm 1.85$ G2 : $5.03 \% \pm 0.85$ \# 